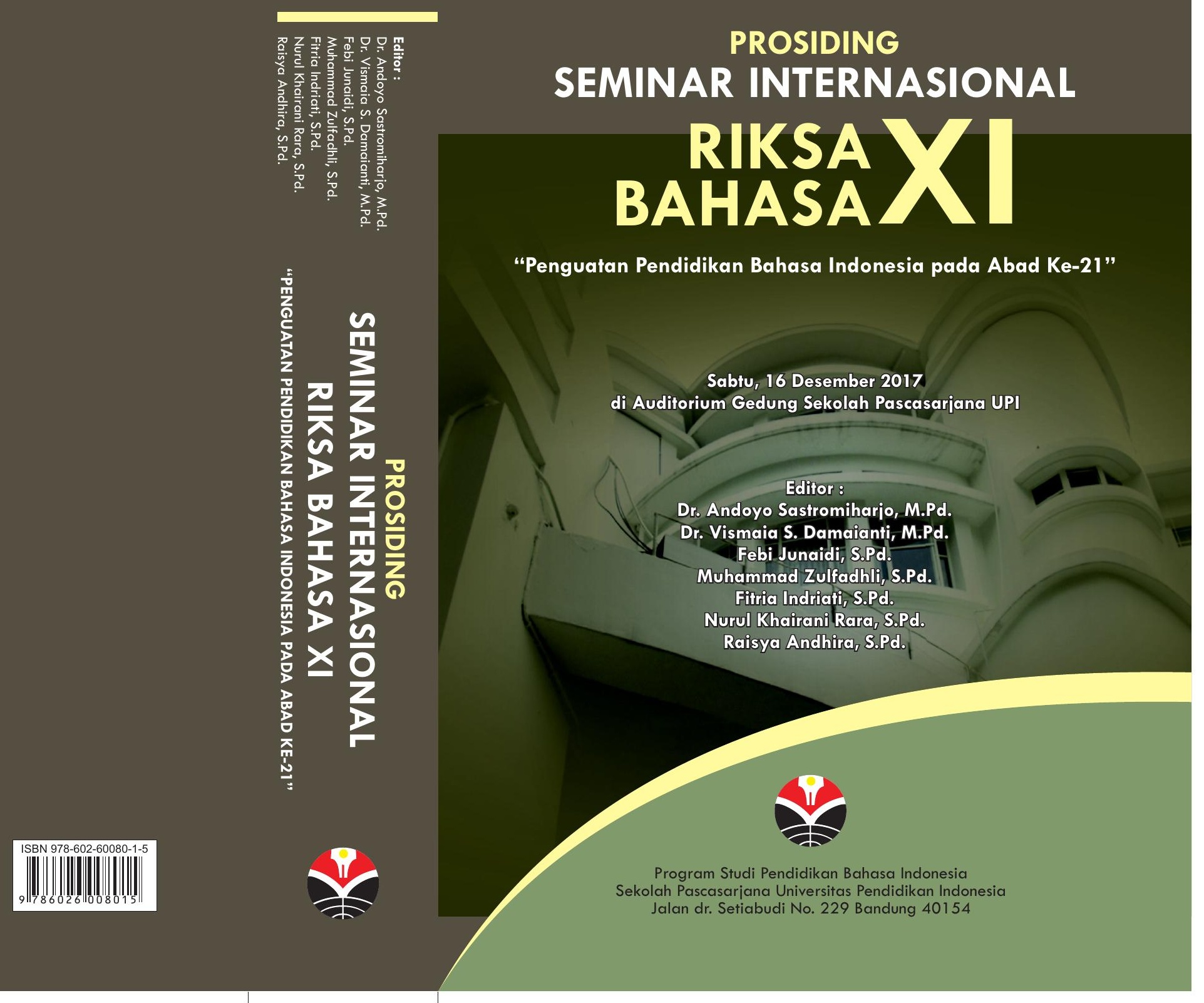




\section{Prosiding}

\section{SEMINAR INTERNASIONAL RIKSA BAHASA XI \\ "Penguatan Pendidikan Bahasa Indonesia pada Abad Ke-21"}

Sabtu, 16 Desember 2017

di Auditorium Gedung Sekolah Pascasarjana UPI

Editor :

Dr. Andoyo Sastromiharjo, M.Pd.

Dr. Vismaia S. Damaianti, M.Pd.

Febi Junaidi, S.Pd.

Muhammad Zulfadhli, S.Pd.

Fitria Indriati, S.Pd.

Nurul Khairani Rara, S.Pd.

Raisya Andhira, S.Pd.

Reviewer :

Dr. Andoyo Sastromiharjo, M.Pd.

Dr. Vismaia S. Damaianti, M.Pd.

Febi Junaidi, S.Pd.

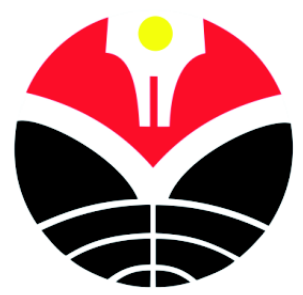

PROGRAM STUDI PENDIDIKAN BAHASA INDONESIA SEKOLAH PASCASARJANA UNIVERSITAS PENDIDIKAN INDONESIA 
Prosiding

Seminar Internasional Riksa Bahasa XI

"Penguatan Pendidikan Bahasa Indonesia pada Abad Ke-21"

\section{Reviewer :}

Dr. Andoyo Sastromiharjo, M.Pd.

Dr. Vismaia S. Damaianti, M.Pd.

Febi Junaidi, S.Pd.

\section{Editor:}

Dr. Andoyo Sastromiharjo, M.Pd.

Dr. Vismaia S. Damaianti, M.Pd.

Febi Junaidi, S.Pd.

Muhammad Zulfadhli, S.Pd.

Fitria Indriati, S.Pd.

Nurul Khairani Rara, S.Pd.

Raisya Andhira, S.Pd.

\section{Desain Cover:}

Rafdysyam, S.Pd.

Cintiana Ermalia, S.Pd.

\section{Setting dan Layout:}

Rendi Pebriana, S.Pd.

Chintia Devi Yurensi, S.Pd.

Ramadani, S.Pd.

Cetakan Pertama: Desember 2017

ISBN 978-602-60080-1-5

\section{Penerbit:}

PROGRAM STUDI PENDIDIKAN BAHASA INDONESIA

SEKOLAH PASCASARJANA UNIVERSITAS PENDIDIKAN INDONESIA

Jl. Dr. Setiabudhi No. 229 Bandung 40154 Telp. 022-2001197

Hak Cipta Dilindungi Oleh Undang-Undang

Dilarang Memperbanyak Karya Tulis Ini Dalam Bentuk Apaun Tanpa Izin Dari Penulis Dan Penerbit. 


\section{PENGANTAR}

Puji syukur kehadirat Tuhan Yang Maha Esa atas segala limpahan rahmat, anugerah, dan berbagai keberkahan sehingga Prosiding Seminar Internasional Riksa Bahasa XI dengan tema "Penguatan Pendidikan Bahasa dan Sastra Indonesia pada Abad ke-21" ini dapat diterbitkan.

Seminar internasional ini merupakan kegiatan tahunan Program Studi Pendidikan bahasa Indonesia SPs Universitas Pendidikan Indonesia. Seminar ini diselenggarakan dengan tujuan untuk meningkatan produktivitas mahasiswa, guru, dosen, ataupun akademisi dalam melakukan penelitian dan penulisan artikel ilmiah yang berkaitan dengan pengajaran bahasa dan sastra Indonesia, ilmu linguistik, bahasa dan budaya daerah, dan kajian pembelajaran bahasa Indonesia untuk Penutur Asing (BIPA). Selanjutnya, kegiatan ini juga diharapkan dapat mendorong penguatan eksistensi bahasa Indonesia baik dalam skala nasioanal maupun internasional. Bahasa Indonesia diharapkan dapat menjadi bahasa pemersatu yang semakin dicintai serta memiliki peran sentral dalam peningkatan budaya literasi bangsa Indonesia.

Selain itu, melalui kegiatan ini, kami mengharapkan terjalinnya komunikasi dan silaturrahmi yang positif dari para pengajar dan peneliti bahasa dan sastra Indonesia sehingga dapat menumbuhkan relasi dan kinerja yang baik untuk mengoptimalkan pengajaran dan pelestarian bahasa dan sastra Indonesia kedepannya. Untuk itu, dalam kesempatan ini, kami mengucapkan terima kasih kepada para pembicara kunci, pemakalah, peserta, dan segenap panitia serta pihak-pihak lainnya yang telah memberikan kontribusi terhadap kesuksesan acara ini sehingga prosiding ini dapat diterbitkan.

Ucapan terima kasih juga kami sampaikan kepada Ketua Program Studi Pendidikan Bahasa Indonesia SPs UPI, Dr. Andoyo Sastromiharjo, M.Pd. atas bimbingan dan arahannya demi kesuksesan acara Riksa Bahasa XI ini. Selanjutnya, atas segala kekurangan yang terdapat pada prosiding ini, kami memohon maaf yang sedalam-dalamnya.

Bandung, 16 Desember 2017

Hormat Kami,

Panitia Riksa Bahasa XI 


\title{
SALAH KAPRAH PEMAKNAAN KATA DALAM BAHASA INDONESIA DAN UPAYA PERBAIKANNYA (STUDI KASUS PADA MEDIA MASSA BERBASIS DARING)
}

\author{
Syahru Ramadan \\ UniversitasPendidikan Indonesia \\ syahru.ramadan.unm@gmail.com
}

\begin{abstract}
ABSTRAK
Salah Kaprah Pemaknaan Kata dalam Bahasa Indonesia dan Upaya Perbaikannya (Studi Kasus pada Media Massa Berbasis Daring). Penelitian ini bertujuan untuk (1) mendeskripsikan katakata yang disalahkaprahkan maknanya oleh media massa berbasis daringdan (2) mendeskripsikan upaya memperbaikinya. Penelitian ini berupa penelitian deskriptif kualitatif. Instrumen yang digunakan adalah peneliti(human instrument) dan dibantu dengan Kamus Besar Bahasa Indonesia (KBBI) sebagai landasan pemaknaan, baik yang berbentuk daring, maupun luring. Metode penyajian data yang digunakan dalam penelitian ini adalah metode simak dengan teknik simak bebas cakap dan catat. Hasil analisis data menunjukkan bahwa (1) Kata-kata yang disalahkaprahkan maknanya dalam media massa berbasis daring berjumlah dua belas kata, yaitu acuh, bergeming, absen, absensi, nuansa, gahar, kosong, seronok, empek-empek, carut-marut, notulen, dan rempong. (2) Adapunupaya memperbaiki pemaknaan itu dengan melalui revitalisasi.Hasil penelitian ini diharapkan menjadi bahan evaluasi dalam menggunakan bahasa Indonesia yang baik dan benar.
\end{abstract}

Kata Kunci: Salah Kaprah Pemaknaan, Makna Leksikal, Media Massa Berbasis Daring.

\section{PENDAHULUAN}

Bahasa Indonesia merupakan bahasa persatuan bangsa Indonesia. Sebagai bahasa persatuan, bahasa Indonesia memiliki dua kedudukan, yakni sebagai bahasa nasional dan sebagai bahasa negara (Halim, 1978). Berdasarkan hal itu, sudah sewajarnya jika bahasa Indonesia memperoleh penghargaan yang tinggi dari masyarakatnya. Akan tetapi, hingga saat ini masih banyak fenomena yang menggambarkan merosotnya penghargaan terhadap bahasa Indonesia. Bahkan, menurut Sartini $(2014, \mathrm{hlm}$. 208) potret bahasa Indonesia saat ini menggambarkan bahasa yang kacau. Kekacauan itu terjadi dalam tataran fonologi, morfologi, sintaksis, dan semantik. Kekacauan itu menurut Kridalaksana (1985) diakibatkan oleh tidak adanya rasa bangga masyarakat Indonesia dalam menggunakan bahasa Indonesia. Mereka lebih bangga menggunakan bahasa asing. Hal itu berdampak pada pemahaman mereka yang kurang mengenai bahasa Indonesia. Hal itu diperparah dengan media massa yang juga seenaknya menggunakan bahasa Indonesia, terutama media massa berbasis daring. Mereka, misalnya dalam hal pemaknaan kata, sering tidak bersumber pada kamus besar bahasa Indonesia (KBBI) dan aturan lainnya.

Jika hal itu diikuti oleh masyarakat pengguna bahasa Indonesia, maka kekacauan tersebut akan menjadi sesuatu yang benar. Keadaan seperti itu disebut dengan istilah salah kaprah, yang merupakan salah satu penyebab pergeseran makna (Meillet dalam Parera (2004, hlm.108). Kekacauan dalam pemaknaan dapat dijumpai dalam beberapa kata, salah satunya adalah "acuh". Beberapa media massa memaknai kata acuh sebagai bentuk ketidakpedulian. Contohnya dalam salah satu judul berita wartaekonomi.co.id edisi 20 Oktober 2017 yang berbunyi "Uni Eropa Acuh Soal Krisis Ekonomi Catalonia." Dalam berita tersebut diungkapkan mengenai sikap Uni Eropa yang tidak peduli dengan krisis ekonomi Catalonia akibat ingin memerdekakan diri dari Spanyol. Sangat jelas tergambar kekeliruan pemaknaan kata acuh tersebut karena makna kata acuh dalam Kamus Besar Bahasa Indonesia (KBBI) adalah peduli. 
Berangkat dari fenomena tersebut, penulis akan meneliti dan menganalisis kesalahankesalahan pemaknaan kata dalam media massa berbasis daring. Kemudian, penulis akan memaparkan upaya untuk mengatasi kesalahan tersebut. Analisis ini nantinya diharapkan dapat menjadi sebuah bahan pembelajaran atau rujukan dalam menggunakan bahasa Indonesia yang baik dan benar sesuai kaidah yang telah ditentukan.

\section{METODE PENELITIAN}

Berdasarkan judul penelitian ini, yakni "Salah Kaprah Pemaknaan Kata dalamBahasa Indonesia dan Upaya Perbaikannya (Studi Kasus pada Media Massa Berbasis Daring)", maka jenispenelitian ini termasuk penelitian deskriptif kualitatif yang bertujuan mendeskripsikan data.

Data dalam penelitian ini berupa kata-kata dan kalimat. Apabila ada angka dalam penelitian ini, hanya untuk mendukung dalam mendeskripsikan hasil penelitian. Data dalam penelitian ini adalah kata dalam kutipan berita yang berjumlah dua belas kata dan sumber datanya adalah berita media massa berbasis daring.

Instrumen penelitian ini adalah peneliti sendiri (human instrument).Peneliti sebagai instrumen pengumpul serta penganalisis data. Peneliti mengedepankan kemampuan memproses data secepatnya serta memanfaatkan kesempatan untuk mengklarifikasi data (Moleong, 2005, hlm. 171). Penelitian ini menggunakan alat bantu berupa Kamus Besar Bahasa Indonesia (KBBI), berwujud daring dan luring, sebagai landasan atau dasar pemaknaan kata.

Dalam penelitian ini, digunakan metode simak dengan teknik simak bebas cakap dan catat sebagai teknik penyajian datanya. Digunakan metode simak karena merupakan penyimakan penggunaan bahasa. Istilah menyimak tidak hanya berkaitandengan penggunaan bahasa lisan, tetapi juga bahasa tulis (Mahsun, 2005, hlm. 92).Pengumpulan data menggunakan teknik simak bebas cakap dan dilanjutkan dengan teknik catat. Teknik inidilakukan dengan cara mencatat dan memilah-milah unsur-unsur yang diteliti.

Kemudian, dalam penelitian ini, dilakukan beberapa langkah dalam menganalisis data, antara lain : 1) membaca dengan teliti berita-berita dalam media massa berbasis daring yang tampil secara heuristik, yakni pembacaan awal hingga akhir berita secara berurutan; 2) mencatat semua kata yang disalahkaprahkan maknanya; 3) mendeskripsikan kesalahan pemaknaan tersebut; 4) memaparkan upaya-upaya untuk mengatasi kesalahan tersebut; dan 5) menarik simpulan atas permasalahan kekeliruan atau salahkaprah dalam memaknai kata bahasa Indonesia.

Selanjutnya, untuk memperkuat keabsahan data dalam penelitian ini, penulis melakukan pemeriksaan dengan serius membaca, mengecek, dan mengintensifkan analisis data. Selain itu, teknik yang digunakan adalah ketekunan pengamatan.

\section{TEMUAN DAN PEMBAHASAN}

Deskripsi hasil penelitian disesuaikandengan tujuan penelitian yaitu: (1) mendeskripsikan kata-kata yang dimaknaisalahatau salah kaprah oleh media massa dan (2) mendeskripsikan upaya memperbaiki kesalahan pemaknaan tersebut.

\section{Kata-Kata yang Mengalami Penyalahkaprahan Makna dalam Media Massa Berbasis Daring}

Berdasarkan hasil temuan, diperoleh dua belas kata yang disalahkaprahkan maknanya oleh media massa berbasis daring. Dua belas kata tersebut dikelompokkan menjadi dua bagian, yakni pemaknaan bentuk baku dan bentuk nonbaku. Pemaknaan bentuk baku meliputi kata acuh, bergeming, absen, absensi, nuansa, gahar, kosong, seronok, empek-empek, dan carut-marut. Kemudian, pemaknaan bentuk nonbaku meliputi kata notulen dan rempong. Berikut pemaparannya. 


\section{Kesalahan Pemaknaan Kata dalam Bentuk Baku}

Berdasarkan hasil temuan, terdapat sepuluh kata baku dalam bahasa Indonesia yang dimaknai keliru atau salah oleh media massa berbasis daring. kata-kata tersebut adalah acuh yang dimaknai tidak peduli, bergeming yang dimaknai bergerak, absen dan absensi yang dimaknai kehadiran atau daftar hadir, nuansa yang dimaknai suasana, gahar yang dimaknai garang atau galak, kosong yang diamaknai nol, seronok yang dimaknai tidak sopan atau tidak senonoh, empek-empek yang dimaknai makanan khas dari tepung terigu, dan carut-marut yang dimaknai kekacauan.

Acuh

Berikut dipaparkan beberapa data mengenai pemaknaan kata-kata tersebut.

Uni Eropa Acuh Soal Krisis Catalonia

Sumber: wartaekonomi.co.idedisi 20 Oktober 2017

Situasi atau konteks berita di atas tentang kondisi Catalonia pasca referendum untuk memerdekakan diri dari Spanyol. Referendum yang telah dilakukan Catalonia membuat krisis terjadi di sana. Presiden Uni Eropa, Donald Tusk, tidak menghiraukan kondisi krisis tersebut dan mengatakan bahwa kondisi Catalonia tidak masuk dalam agenda KTT Dewan Uni Eropa.

Dilihat dari konteksnya, maka makna acuh dalam judul berita tersebut adalah tidak peduli. Makna tersebut bertentangan dengan makna yang ada dalam KBBI. Dalam KBBI sendiri, makna acuh adalah peduli.

\section{Bergeming}

Murray Tak Bergeming Digoda Penari Perut

Sumber: okezone.comedisi 26 Februari 2015

Situasi atau konteks berita di atas tentang petenis Andy Murray yang tidak terpengaruh oleh aksi penari perut yang datang menghampirinya. Hiburan tersebut terjadi pada saat pesta makan malam dalam ajang Dubai Tennis Championship. Andy Murray tetap diam dan tidak beranjak dari tempat duduk ketika penari tersebut mengajaknya berdansa.

Jika melihat konteks isi berita di atas, maka makna bergeming adalah bergerak. Makna tersebut tidak sejalan dengan makna dalam KBBI. Dalam KBBI sendiri, makna bergeming adalah diam, sehingga jika konteks kalimat tentang kondisi tidak bergerak, maka penggunaan kata yang tepat cukup dengan bergeming saja dan tidak perlu ditambahkan dengan kata tak atau tidak sebelumnya.

\section{Absen}

Menpan: Banyak PNS Datang ke Kantor Hanya untuk Absen Saja, Bukan Kerja

Sumber: detiknews.comedisi 26 Agustus 2016

Situasi atau konteks berita tersebut tentang komentar Menteri Pendayagunaan Aparatur Negara mengenai PNS yang hadir ke kantor hanyauntuk menyetor sidik jari di daftar hadir tanpa melaksanakan tugas dan fungsinya secara benar. Jika melihat konteks tersebut, makamakna absen dalam judul beritadi atas adalah mengisi daftar hadir. Makna itu bertentangan dengan makna dalam KBBI. Dalam KBBI, absen bermakna tidak hadir.

\section{Gahar}

Wajah "Gahar" Nagita Slavina Saat Berpose Duduk Bersila di Atas Kaki Fajar Putra

Sumber: tribunnews.comedisi 16 Mei 2017 
Konteks berita tersebut tentang sesi pemotretan yang dilakukan kepada selebriti, Nagita Slavina. Dalam sesi pemotretan tersebut, Nagita diarahkan untuk membuat ekspresi galak. Kesan tersebut diperkuat dengan warna lipstick gelap yang dia gunakan.

Berdasarkan konteks tersebut, maka makna gahar dipadankan dengan makna galak atau garang. Kata gahar dalam KBBI tidak dapat dipadankan dengan kata garang karena memiliki makna yang berbeda. Dalam KBBI, gahar bermakna gosok kuat-kuat.

\section{Seronok}

Beredar Foto Seronok Diduga Siswi SMK Kandeman Kabupaten Batang

Sumber :garudacitizen.comedisi 3 Juni 2016

Situasi atau konteks berita tersebut tentang beredarnya foto seorang siswi dengan pose vulgar atau tidak sopan. Berdasarkan konteks tersebut, makna seronok dalam judul berita di atas diartikan tidak senonoh atau tidak sopan. Makna seronok tersebut tidak sejalan dengan makna dalam KBBI. Dalam KBBI, makna seronok adalah bagus atau sedap dilihat.

\section{Empek-Empek}

Kisah Fikhri, Bocah Putus Sekolah Penjual Empek-Empek

Sumber :kompas.comedisi 15 Agustus 2017

Situasi atau konteks berita tersebut tentang seorang anak yang putus sekolah dan membantup erkonomian orang tuanya dengan berjualan makanan. Makanan yang dimaksud adalah pempek. Berdasarkan konteks tersebut, kata empek-empek dipadankan dengan kata pempek yang merujuk pada sejenis makanan. Dalam KBBI, kata empek-empek dan pempek tidak dapat dipadankan karena kata empek-empek tidak bermakna makanan, melainkan bermakna kakek-kakek yang tua sekali.

\section{Carut-Marut}

Sri Mulyani dan Carut-Marut Pajak Penulis, 5 Berita Populer Ekonomi.

Sumber: kompas.comedisi 15 September 2017

Situasi atau konteks berita tersebut tentang Menteri Keuangan, Sri Mulyani yang dibuat pusing mengenai pajak penulis. Para penulis meminta Sri Mulyani untuk meninjau ulang besaran Norma Penghitungan Penghasilan Netto (NPPN) pajak penulis karena besaran NPPN penulis sangat berpengaruh kepada pendapatan para penulis.Jika memperhatikan konteks tersebut, maka makna carut-marut dalam judul berita di atas adalah kacau atau tidak keruan. Makna tersebut tidak sesuai dengan makna dalam KBBI. Dalam KBBI, carut-marut bermakna segala jenis perkataan keji.

\section{Kesalahan Pemaknaan Kata dalam Bentuk Nonbaku}

Dalam media massa berbasis daring, terdapat dua kata nonbaku yang dimaknai keliru atau tidak sesuai dengan rujukan bentuk bakunya dalam KBBI. Kata-kata tersebut adalah: (1) notulen yang merupakan bentuk tidak baku dari notula dan (2) rempong yang merupakan bentuk tidak baku dari rimpung. Berikut pemaparan makna kata berdasarkan pada data yang ditemukan.

Notulen

Ahok Tegur Notulen Rapat yang Pakai Tulisan Tangan

Sumber :viva.co.idedisi 24 Oktober 2012

Situasi atau konteks berita tersebut tentang mantan Gubernur DKI Jakarta, Ahok yang menegur petugas pencatat hasil rapat saat pertemuan dengan perwakilan serikat pekerja di kantornya. Berdasarkan konteks itu, makna notulen adalah petugas pencatat hasil rapat atau diskusi. Makna tersebut tidak sejalan dengan makna dalam KBBI karena makna notulen dalam KBBI adalah catatan hasil rapat atau diskusi. Notulen merupakan bentuk tidak baku dari notula. 


\section{Rempong}

Saat Kahiyang Jokowi Geram dengan Ibu-Ibu yang "Rempong” Soal Jodohnya

Sumber :kompas.comedisi 24 Agustus 2017

Konteks atau situasi dalam berita di atas adalah kegeraman Putri Presiden JokoWidodo terhadap komentar salah seorang warganet yang mengkritik jodoh pilihan putri presiden. Putripresiden, Kahiyang, menyebut warga net itu sebagai ibu-ibu rempong.Berdasarkan konteks isi berita tersebut, maka makna rempong dalam judul berita di atas adalah ribet mengurusi urusan orang lain. Makna itu tidak sesuai dengan makna rempong dalam KBBI. Kata rempong dalam KBBI merupakan bentuk tidak baku dari rimpung yang bermakna terikat kakinya.

\section{Upaya Memperbaiki Kekeliruan Pemaknaan Kata}

Media massa berbasis daring, berdasarkan temuan di atas, masih keliru dalam memaknai beberapa kata. Kekeliruan tersebut jika dibiarkan akan berujung pada salah kaprah. Untuk memperbaiki kondisi tersebut, maka diperlukan upaya revitalisasi dalam bahasa Indonesia. Revitalisasi sendiri adalah upaya untuk mengembalikan bahasa Indonesia kepada kaidah-kaidah yang benar dan sesuai dengan aturan yang berlaku (Sartini, 2014, hlm. 209).

Upaya pengembalian bahasa Indonesia ke kaidah yang benar dapat dilakukan melalui pemberian pemahaman kepada para jurnalis mengenai makna kata yang benar. Para jurnalis dalam menyusun berita harus berpedoman pada KBBI dan acuan lainnya. Hal ini untuk menjaga agar pergeseran makna tidak terjadi, yang akan berujung pada peningkatan kekacauan bahasa Indonesia.

\section{KESIMPULAN}

Pemaknaan kata dari media massa berbasis daring, pada umumnya masih keliru. Kekeliruan itu tampak pada pemaknaan dua belas kata, antara lain: acuh, bergeming, absen, absensi, nuansa, gahar, kosong, seronok, empek-empek, carut-marut, notulen, dan rempong. Jika kekeliruan itu tetap dibiarkan, maka akan berujung pada salah kaprah bagi masyarakat karena sering membaca media massa tersebut. Maka dari itu, diperlukan sikap dan tindakan untuk mengatasi kekeliruan pemaknaan itu. Tindakan yang dapat dilakukan adalah merevitalisasi bahasa Indonesia. Selain revitalisasi, diharapkan juga kepada pemerintah Indonesia melalui lembaga yang terkait untuk mengambil sikap mengenai fenomena kebahasaan ini.

Selain itu, diharapkan juga agar peneliti lain melirik fenomena ini dan mengembangkan penelitian sejenis agar kesalahan dalam pemaknaan kata semakin diminimalkan. Penelitian ini dapat dijadikan sebagai batu loncatan untuk meneliti lebih dalam tentang fenomena pemaknaan dalam bahasa Indonesia.

\section{DAFTAR PUSTAKA}

Arifin, M. (2015). "Mempertahankan bahasa Indonesia sebagai jati diri bangsa”.Prosiding seminar nasional bulan bahasa UNIB(hlm. 82-87). Bengkulu: Penerbit FKIP UNIB.

Aslinda \&Syafyahya, L. (2010). Pengantar sosiolinguistik. Bandung: Refika Aditama.

Chaer, A \& Leonie, A. (2010). Sosiolinguistik perkenalan awal. Jakarta : Rineka Cipta.

Departemen Pendidikan Nasional. (2013). Kamus besar bahasa Indonesia edisi keempat. Jakarta: Gramedia Pustaka Utama. 
Halim, A. (1978). Sikap bahasa dan pelaksanaan kebijaksanaan bahasa nasional. pengajaran bahasa dan sastra, 6(6), 11-26.

Kridalaksana, H. (1985). Sikap dan fungsi bahasa. Flores: Nusa Indah.

Kementerian Pendidikan dan Kebudayaan Republik Indonesia. (2016). KBBI Daring. [Online]. Diakses darihttps://kbbi.kemdikbud.go.id/Cari/Index.

Mahsun. (2005). Metode penelitian bahasa: tahapan strategi, metode, dan tekniknya. Jakarta: Raja Grafindo.

Maksan, M. (1994). Ilmu bahasa. Padang: IKIP Padang Press.

Moleong, L. J. (2005). Metodologi penelitian kualitatif. Edisi Revisi. Cetakan Kedua puluh satu. Bandung: Remaja Rosdakarya.

Parera, J.D. (2004). Teori semantik. Jakarta : Erlangga.

Sartini, N. W. (2014). Revitalisasi bahasa Indonesia dalam konteks kebahasaan. masyarakat, kebudayaan dan politik, 27(4), 206-210.

Setyadi, A. (2014). Pemakaian kompetitif: macam bidang dan penyebab. humanika, 20(2), 7481 . 